\title{
Estimation of productive losses caused by withdrawal of antibiotic growth promoter from
}

\section{pig diets - Meta-analysis}

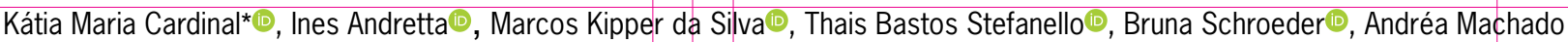 \\ Leal Ribeiro(1)
}

Universidade Federal do Rio Grande do Sul/FA - Depto. de Zootecnia - Lab. de Ensino Zootécnico, R. Bento Gonçalves, 7712 - 91540-000 - Porto Alegre, RS - Brasil.

*Corresponding author <katia.zootecnia@hotmail.com>

Edited by: Melissa Izabel Hannas

Received September 10, 2020

Accepted November 23, 2020
ABSTRACT: This study was designed to simulate productive and economic losses due to the withdrawal of antibiotic growth promoters (AGP) from pig diets. Articles that compared diets with AGP (AGP+) or without AGP (AGP-) for pigs were collected from electronic databases and the performance results were entered in a database. A meta-analysis was performed following the sequence: graphical analysis, correlation, and variance-covariance. The performance results observed in the meta-analysis, feed cost, and AGP costs were used to build equations to estimate the economic effect of withdrawing AGP. The database comprised 81 scientific articles containing 103 experiments totalizing 42,923 pigs. Avilamycin (24.7\%) was the most frequent AGP in the database, followed by Colistin (15.4\%), Tiamulin (11.7\%), Tylosin (8.0\%), Lincomycin $(9.4 \%)$, and Bacitracin $(5.4 \%)$. Weight gain $(p<0.05)$ increased in AGP+ diets during postweaning (6.5\%). However, there was no effect of AGP on weight gain of growing-finishing pigs. There was better $(p<0.05)$ feed conversion in pigs fed AGP + diets in all rearing phases. Weight gain and feed conversion improved $(p<0.05)$ with the addition of Avilamycin, Bacitracin, and Tylosin. AGP withdrawal in the post-weaning phase increased feed costs by US $\$ 0.86$ per animal and in growing-finishing phase the increase was US\$ 3.11. Thus, pigs fed AGP+ diets have a better performance than pigs fed AGP- diets and the withdrawal of AGP increases feed costs.

Keywords: addditive, feed conversion, feed cost, productive cost, swine

\section{Introduction}

Antimicrobial additives have been used in animal feed since the 1950s; however, changes in the use of antibiotics and antibiotic growth promoters (AGP) in several countries indicate a trend to reduce the use of these substances. Sweden banned AGP use in animal production in 1986, while the European Union banned AGP use in 2006. Brazil banned the use of Colistin in 2016 as well as the use of Tylosin, Tiamulin, and Lincomycin in 2020 (Davies and Walsh, 2018; MAPA, 2020) In Mar 2019, the Food and Drugs Administration (USA) published a revised guidance on the use of antibiotics and AGP for the industry in the United States (FDA, 2019). Several other countries have announced strategies to restrict and/or ban the use of AGP in animal production, namely Vietnam, India, Bangladesh, Bhutan, and Indonesia (Kahn, 2016; Goutard et al., 2017; USDA, 2016). The pressure to reduce and/or ban the use of antibiotics and AGP in animal production is linked to the selection of antibiotic-resistant bacteria, which results in environmental and economic problems worldwide (Tang et al., 2017; WHO, 2018).

Challenges to the health and welfare of pigs presented by modern production practices justify the use of AGP (Verstegen and Williams, 2002; Fairbrother et al., 2005). However, there is considerable effect on the weight gain and feed conversion responses to AGP. Many studies have reported no differences in the performance of animals fed an AGP diet in the absence of health problems (Li et al., 2012; Yang et al., 2012; Perina et al.,
2014; Long et al., 2018). Conversely, other studies have reported positive effects of AGP on pig weight gain and feed conversion (Valchev et al., 2009; Yoon et al., 2014; Li et al., 2017; Silva et al., 2016).

It is evident that the process of restricting and banning the use of AGP is increasing worldwide and this process is irreversible. It is extremely necessary to analyze the consequences of withdrawing this additive from pig production, especially in terms of performance responses of the animals and the economic impact on feed costs. Therefore, this study investigated the impact on performance and productive costs due to the withdrawal of AGP from pig diets.

\section{Materials and Methods}

This study is part of a larger project that used the same methodology in two studies. Both used metaanalysis to obtain performance responses and, based on performance data and data from industry, equations were generated to estimate the economic impact. In the first study, analyses were performed to obtain the results of performance and economic effects on broiler production (Cardinal et al., 2019).

\section{Search, data filtering and coding}

Articles presenting experimental results of pig performance due to the use of AGP in diets were searched on Google Scholar, ScienceDirect, Scopus, Scielo, and PubMed, using the keywords: "antibiotic 
growth promoter" and "performance" in addition to the terms "swine" or "pig". As a strategy, "AND", "OR" and "*" were used to aid in the search, aiming to find as many studies as possible. The terms were tested in three languages: English, Spanish, and Portuguese. The references cited in the selected articles were analyzed to find additional articles, which were not in the search results. The search in different online databases and additional searches aimed to avoid publication bias. Following identification, all articles were evaluated by two reviewers, and the agreement of both reviewers was necessary to exclude a record. The articles were evaluated according to their relevance and quality to expose performance results of pigs that received diets with or without AGP, without the presence of a health challenge thus meeting the meta-analysis objectives. The following factors in a checklist were considered for the exclusion of pre-selected manuscripts: presence of health challenge (such as Escherichia Coli, or Salmonella Typhimurium), slow-growing breeds, absence of control treatment, inconsistent methodological data, error of statistical design (such as factorial design analyzed as a simple difference in means), and gross errors in result data. The criteria for publication selection were: (1) in vivo experimental evaluation of diets with AGP (AGP+) or without AGP (AGP-), no other growth-promoting additive could be present in the AGP- diet; (2) antibiotics were used in subtherapeutic doses, as recommended for growth promoters (Sindirações, 2009); (3) the AGP used was allowed in the Brazilian standard legislation of 2016 ; (4) the experimental pigs were in post-weaning, growing, or finishing phases; (5) the rates of feed intake, weight gain, and feed conversion or feed efficiency were stated; (6) year of publication was between 1990 and 2018.

The methodology described by Sauvant et al., 2005 and Lovatto et al., 2007 was used for the database construction and data encoding. Results of body weight, feed intake, weight gain, and feed conversion were entered an electronic spreadsheet, in addition to other variables, such as genetic strain, age, sex, dietary nutritional composition, and duration of the experimental period, wich were included to perform a descriptive analysis of the studies. Some codes were inserted into the database to create specific groups and to insert grouping criteria into the statistical model, such as presence (AGP +) or absence (AGP-) of AGP and each antibiotic (e.g.: " $\mathrm{C}$ " for Colistin and " $\mathrm{T}$ " for Tylosin). Other codes were inserted into the statistical model to evaluate the effect of the study and the trial, allowing to assess the variability of the compiled studies.

\section{Composition of the database}

Eighty-one articles, 103 experiments, were inserted in the database. The articles published between 1998 and 2018 were in greater number, representing $97 \%$ (Figure $1)$, and studies were conducted in China (20\%), Brazil

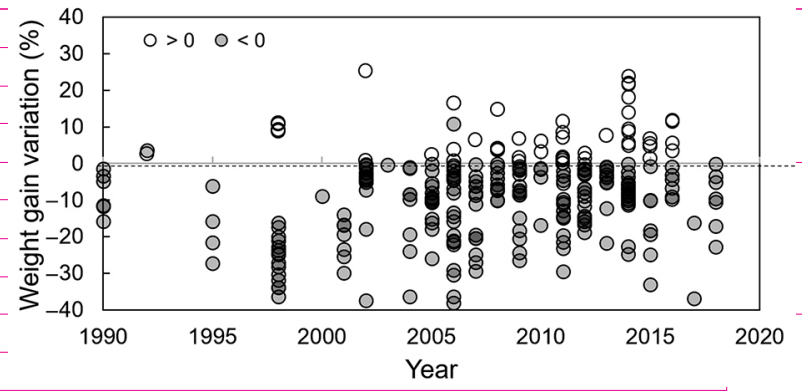

Figure 1 - Percentage variation calculated for each treatment containing antibiotic growth promoter (AGP+) in relation to the opposite treatment without antibiotic growth promoters (AGP-). Data collected from the studies included in the database, according to the year of publication.

(16\%), the United States of America (16\%), Canada $(9 \%)$, and other countries (31\%), such as Greece, Spain, Poland, and Korea. The sum of pigs used in all trials was 42,932 , with 8.1 and $15.7 \mathrm{~kg}$ as the average of the initial and final body weights of post-weaning and 42.0 and $89.1 \mathrm{~kg}$ of growing/finishing pigs, respectively. In the total of selected articles, the most studied phase was post-weaning $(70 \%$ of the studies; average age at weaning: 23 days, minimum: 14 days, maximum: 35 days), and the performance of pigs in the growingfinishing phase was evaluated in $20 \%$ of the articles. The authors did not describe which rearing phase was studied in $10 \%$ of the selected articles. The average duration of the trials analyzing post-weaning phase was 21 days (minimum: 7 days; maximum: 50 days), and the average duration of the trials analyzing growth-finishing phase was 57 days (minimum: 14 days; maximum: 134 days). The periods evaluated in the meta-analysis always considered the use of AGP. The area provided per pig varied from 0.2 to $1.5 \mathrm{~m}^{2}$ for post-weaning and from 0.6 to $3.0 \mathrm{~m}^{2}$ for growing-finishing pigs. Avilamycin was the antibiotic most cited in the selected articles $(24.7 \%$ of AGP + treatments), followed by Colistin (15.4\%), Tiamulin (11.7\%), Tylosin (8.0\%), Lincomycin (9.4\%), and Bacitracin (5.4\%). Mixed-sex groups were used in $47 \%$ of the reviewed studies and treatments with maleonly or female-only groups represented $7 \%$ and $2 \%$ of the total, respectively. The sex of the pigs was not described in $44 \%$ of the articles.

\section{Statistical analysis}

Series of graphical analyses were used to assess the data distribution and obtain a general view of their consistency and variance heterogeneity. Based on these analyses, correlation hypotheses were formulated to define the statistical models (Lovatto et al., 2007). During this step, data distribution per year, country, and for the presence or absence of AGP were evaluated. The performance data of AGP- treatments were relativized according to their respective $\mathrm{AGP}+$ to estimate the 
impact (percentage variation) of AGP withdrawal. Additionally, the relationships between and within studies were evaluated.

The variance-covariance analyses were conducted using the GLM procedure in the Minitab 18 statistical package, the effects of sex of the animals, area of pen space provided per pig $\left(\mathrm{m}^{2} \mathrm{pig}^{-1}\right)$, and year of publication were tested. However, the factors were not significant $(p$ $>0.05)$ and thus all three factors were removed from the model. A mixed model was applied, considering treatments as a fixed effect, while the inter-study was a random effect, and body weight was used as a co-factor $(p<0.05)$. The variables analyzed were feed intake, weight gain, and feed conversion. The analyses were grouped by rearing phase (post-weaning and growthto-finishing) when the information about the phase of rearing was provided in the original publication. Individual analyses were performed for the main AGP in the database. Overall performance was evaluated for each AGP molecule. In these analyses, we considered the studies with both rearing phases and the studies without phase identification (information not provided in the publication). The result of the analysis for residual distribution was normal.

\section{Impact on feed costs}

The results obtained in the meta-analysis were used to develop an equation to simulate the economic impact of AGP withdrawal from pig diets, particularly on feed costs in a Brazilian scenario. Brazil was chosen for this simulation as it is a large pork producer and exporter. In this analysis, the authors generated an overview of AGP withdrawal, using values that do not take into account the specificity of each AGP in the performance results. However, the equation described can be used to conduct a specific simulation for an AGP. The simulation (Equation 1 to 4 and Table 1) considered the target weight gain and feed conversion for each phase (in $\mathrm{AGP}+$ diets), the variation in feed conversion (obtained from the meta-analysis), as well as feed (cost was based on the price of ingredients plus operating costs) and AGP costs. Information on feed and AGP costs was provided by a Brazilian feed mill.

Feed cost of per animal $=\alpha \times\left(\frac{\beta}{1000}\right)$

Table 1 - Inputs to estimate the economic impact caused by the withdrawal of antibiotic growth promoters (AGP) from pig diets.

\begin{tabular}{lcc}
\hline Inputs & Post-weaning & Growing-Finishing \\
\hline Weight gain, kg & 20 & 90 \\
Feed conversion target (AGP+), kg kg-1 & 1.64 & 2.56 \\
Feed conversion change ${ }^{1}, \%$ & 3.59 & 5.51 \\
Feed cost, US\$ kg-1 & 0.74 & 0.25 \\
AGP cost, US\$ kg-1 of inclusion & 45.3 & 45.3 \\
\hline Feed conversion change: the difference between diets with and without & antibiotic growth promoters obtained by the meta-analysis.
\end{tabular}

where: $\alpha$ : feed intake of the phase $\left(\mathrm{kg} \mathrm{d}^{-1}\right)$ and $\beta$ : cost of feed (US $\left.\$ t^{-1}\right)$.

Feed intake of the phase $=\tau \times$ FCR

where: $\tau$ : weight gain of the phase $(\mathrm{kg})$ and FCR: feed conversion $\left(\mathrm{kg} \mathrm{kg}^{-1}\right)$.

Feed cost: $\mu+y$

where: $\mu$ : feed price (US $\$ t^{-1}$ ) and $y:$ AGP price $\left(U S \$ t^{-1}\right)$.

The sensitivity analysis is used to predict the result generated by changes in variables or activities in a process to measure the sensitiveness of the process when a change occurs (Saltelli et al., 2000). The sensitivity analysis was performed using the key variables "feed conversion" and "AGP price". The equations developed to calculate the impact on feed costs were used to perform the sensitivity analysis. Feed conversion data were simulated to obtain $0.0,1.0,2.0,3.0,4.0$, and $5.0 \%$ of difference between AGP +/AGP-. The AGP price was reduced by half or increased by $1.0,2.0,3.0,4.0$, and 5.0 times compared to the current price. When the value of the impact on feed costs was greater than zero (representing an increase in the pig production cost), the AGP withdrawal was considered an economically sound strategy, and when the impact value was below zero, the AGP use was considered a better economic decision to avoid financial loss. The analysis was performed using Microsoft Excel 2016.

Only the results of feed cost and changes in performance were considered in this study. Other factors, such as veterinary cost, health costs, and time of use of the facilities were not included in the model for economic impact.

\section{Results}

\section{Performance}

The withdrawal of AGP decreased the performance of pigs. A negative variation in weight gain was observed in $83 \%$ of comparisons between the treatments AGP + and AGPv (Figure 1). Pig feed conversion was better in AGP + treatment in $77 \%$ of comparisons between treatments.

In the meta-analysis, no difference was observed $(p>0.05)$ in feed intake between the AGP + and AGPtreatments in all the examined production phases. Weight gain was better in post-weaning phase $(p<0.05$; Table 2) when the AGP + diet was used; however, no changes were detected during the growing-finishing phase $|p\rangle$ 0.05). The AGP + diet resulted in $6.5 \%$ weight gain in the post-weaning phase. The effect on feed conversion was improved $(p<0.05)$ in pigs fed AGP + diet, in all rearing phases. The greater effect of feed conversion was $5.5 \%$ in the growing-finishing phase, followed by the post-weaning phase with $3.5 \%$. 
Feed intake was not influenced by AGP + and AGP- treatments ( $p>0.05$; Table 3$)$, regardless of the AGP molecule analyzed. The addition of Colistin, Tiamulin, and Lincomycin did not influence weight gain between AGP + and AGP - diets ( $p>0.05)$, while the addition of Avilamycin, Bacitracin, and Tylosin showed a positive effect on weight gain and feed conversion $(p$ $<0.05)$.

\section{Impact on feed costs}

The AGP withdrawal in the post-weaning phase increased the feed cost by US $\$ 0.86$ per animal. In the growingfinishing phase, the increase was more pronounced, with a rate of US\$3.11 per animal (Table 4).

In the sensitivity analysis (Figure 2), "NO" indicates a scenario where the AGP withdrawal has no

Table 2 - Performance (obtained by meta-analysis*) of pigs fed with diets containing antibiotic growth promoters (AGP+) or without antibiotic growth promoters (AGP-).

\begin{tabular}{|c|c|c|c|c|c|c|}
\hline \multirow{2}{*}{ Variable } & \multicolumn{2}{|c|}{ Treatments } & \multirow{2}{*}{$p$} & \multirow{2}{*}{ RSE } & \multirow{2}{*}{$\mathrm{R}^{2}$} & \multirow{2}{*}{$\%$} \\
\hline & $\mathrm{AGP}+$ & AGP- & & & & \\
\hline \multicolumn{7}{|l|}{ Post-weaning } \\
\hline Feed intake, $\mathrm{kg} \mathrm{d}^{-1}$ & 0.609 (n:197) & $0.592(\mathrm{n}: 190)$ & 0.508 & 0.251 & 58.33 & 2.79 \\
\hline Weight gain, $\mathrm{kg} \mathrm{d}^{-1}$ & $0.365(n: 202)$ & $0.341(n: 195)$ & 0.039 & 0.115 & 56.85 & 6.57 \\
\hline Feed conversion, $\mathrm{kg} \mathrm{kg}^{-1}$ & 1.642 (n:194) & $1.701(n: 187)$ & 0.008 & 0.213 & 62.24 & 3.59 \\
\hline \multicolumn{7}{|l|}{ Growing/ finishing } \\
\hline Feed intake, $\mathrm{kg} \mathrm{d}^{-1}$ & 2.095 (n:69) & $2.080(n: 46)$ & 0.855 & 0.317 & 65.79 & 0.71 \\
\hline Weight gain, $\mathrm{kg} \mathrm{d}^{-1}$ & $0.805(n: 70)$ & $0.769(n: 47)$ & 0.078 & 0.101 & 68.65 & 4.47 \\
\hline Feed conversion, $\mathrm{kg} \mathrm{kg}^{-1}$ & $2.565(n: 69)$ & $2.704(n: 46)$ & 0.038 & 0.232 & 54.49 & 5.51 \\
\hline
\end{tabular}

Table 3 - Overall performance* (obtained by meta-analysis) of pigs fed with diets containing specific antibiotic growth promoters (AGP+) or without antibiotic growth promoters (AGP-).

\begin{tabular}{|c|c|c|c|c|c|c|}
\hline \multirow{2}{*}{ Variable } & \multicolumn{2}{|c|}{ Treatments } & \multirow{2}{*}{$p$} & \multirow{2}{*}{ RSE } & \multirow{2}{*}{$\mathrm{R}^{2}$} & \multirow{2}{*}{$\%$} \\
\hline & $\mathrm{AGP}+$ & AGP- & & & & \\
\hline \multicolumn{7}{|l|}{ Colistin } \\
\hline Feed intake, $\mathrm{kg} \mathrm{d}^{-1}$ & $0.690(n: 42)$ & 0.674 (n:42) & 0.526 & 0.117 & 96.98 & 2.32 \\
\hline Weight gain, $\mathrm{kg} \mathrm{d}^{-1}$ & 0.388 (n:45) & $0.374(\mathrm{n}: 45)$ & 0.439 & 0.083 & 87.96 & 3.61 \\
\hline Feed conversion, $\mathrm{kg} \mathrm{kg}^{-1}$ & $1.645(n: 42)$ & $1.641(\mathrm{n}: 42)$ & 0.917 & 0.160 & 79.67 & 0.24 \\
\hline \multicolumn{7}{|l|}{ Avilamycin } \\
\hline Feed intake, $\mathrm{kg} \mathrm{d}^{-1}$ & $0.759(n: 60)$ & $0.755(n: 57)$ & 0.838 & 0.123 & 95.86 & 0.53 \\
\hline Weight gain, $\mathrm{kg} \mathrm{d}^{-1}$ & $0.403(n: 61)$ & $0.371(n: 58)$ & 0.039 & 0.091 & 81.04 & 7.94 \\
\hline Feed conversion, $\mathrm{kg} \mathrm{kg}^{-1}$ & $1.714(\mathrm{n}: 60)$ & $1.806(n: 57)$ & 0.008 & 0.183 & 87.27 & 5.37 \\
\hline \multicolumn{7}{|l|}{ Bacitracin } \\
\hline Feed intake, $\mathrm{kg} \mathrm{d}^{-1}$ & $0.675(n: 10)$ & $0.750(n: 10)$ & 0.253 & 0.132 & 97.14 & 11.1 \\
\hline Weight gain, $\mathrm{kg} \mathrm{d}^{-1}$ & $0.289(n: 12)$ & $0.221(n: 12)$ & 0.049 & 0.108 & 59.11 & 23.5 \\
\hline Feed conversion, $\mathrm{kg} \mathrm{kg}^{-1}$ & $1.802(n: 10)$ & $1.915(\mathrm{n}: 10)$ & 0.048 & 0.126 & 96.49 & 6.27 \\
\hline \multicolumn{7}{|l|}{ Tylosin } \\
\hline Feed intake, $\mathrm{kg} \mathrm{d}^{-1}$ & $1.497(\mathrm{n}: 22)$ & $1.490(n: 22)$ & 0.898 & 0.192 & 95.90 & 0.47 \\
\hline Weight gain, $\mathrm{kg} \mathrm{d}^{-1}$ & $0.607(n: 22)$ & $0.541(n: 22)$ & 0.036 & 0.119 & 86.54 & 10.8 \\
\hline Feed conversion, $\mathrm{kg} \mathrm{kg}^{-1}$ & $2.005(n: 22)$ & $2.172(n: 22)$ & 0.045 & 0.195 & 86.08 & 8.33 \\
\hline \multicolumn{7}{|l|}{ Tiamulin } \\
\hline Feed intake, $\mathrm{kg} \mathrm{d}^{-1}$ & $0.647(n: 13)$ & $0.689(\mathrm{n}: 13)$ & 0.177 & 0.075 & 98.18 & 6.49 \\
\hline Weight gain, $\mathrm{kg} \mathrm{d}^{-1}$ & $0.334(n: 13)$ & $0.322(n: 13)$ & 0.391 & 0.036 & 94.10 & 3.59 \\
\hline Feed conversion, $\mathrm{kg} \mathrm{kg}^{-1}$ & $1.554(\mathrm{n}: 13)$ & $1.675(n: 13)$ & 0.080 & 0.165 & 89.02 & 7.79 \\
\hline \multicolumn{7}{|l|}{ Lincomycin } \\
\hline Feed intake, $\mathrm{kg} \mathrm{d}^{-1}$ & $0.468(n: 13)$ & $0.479(\mathrm{n}: 13)$ & 0.678 & 0.065 & 97.06 & 2.35 \\
\hline Weight gain, $\mathrm{kg} \mathrm{d}^{-1}$ & $0.210(n: 13)$ & $0.195(n: 13)$ & 0.514 & 0.055 & 91.03 & 7.14 \\
\hline Feed conversion, $\mathrm{kg} \mathrm{kg}^{-1}$ & $1.673(n: 13)$ & $1.7818(n: 13)$ & 0.098 & 0.157 & 60.75 & 6.50 \\
\hline
\end{tabular}




\begin{tabular}{|c|c|c|c|c|c|c|}
\hline \multirow{11}{*}{ 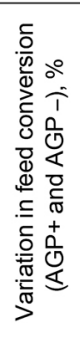 } & \multicolumn{6}{|c|}{ Variation in AGP price } \\
\hline & $\mathrm{X} / 2$ & $x^{1}$ & $\mathrm{X} 2$ & $\mathrm{X} 3$ & $\mathrm{X} 4$ & $x 5$ \\
\hline & \begin{tabular}{l|l}
$0 \mathrm{NO}^{2}$ \\
\end{tabular} & NO & NO & NO & NO & NO \\
\hline & 0.15 YES $^{3}$ & NO & NO & NO & NO & NO \\
\hline & 0.3 YES & YES & NO & NO & NO & NO \\
\hline & 0.5 YES & YES & YES & NO & NO & NO \\
\hline & 1.0 YES & YES & YES & YES & YES & YES \\
\hline & 2.0 YES & YES & YES & YES & YES & YES \\
\hline & 3.0) YES & YES & YES & YES & YES & YES \\
\hline & 4.0 YES & YES & YES & YES & YES & YES \\
\hline & $5.0 \mid$ YES & YES & YES & YES & YES & YES \\
\hline
\end{tabular}

Figure 2 - The sensitivity analysis for antibiotic growth promoter (AGP) withdrawal from pig diets according to the change in the additive price and the change between feed conversion rates with and without AGP; ${ }^{1 X}=$ current price of antibiotic growth promoter; ${ }^{2} \mathrm{NO}=$ the scenario of rearing pigs without AGP has no impact on feed costs; ${ }^{3} Y E S=$ the scenario where the use of AGP is expected to have no impact on feed costs.

Table 4 - Simulation of the economic impact of removing antibiotic growth promoters (AGP).

\begin{tabular}{|c|c|c|c|}
\hline & \multicolumn{2}{|c|}{ Treatments } & \multirow{2}{*}{ Change } \\
\hline & $\mathrm{AGP}+$ & AGP- & \\
\hline & & & $\%$ \\
\hline \multicolumn{4}{|l|}{ Post-Weaning } \\
\hline Feed cost, US\$ per animal & 24.50 & 25.37 & 3.42 \\
\hline \multicolumn{4}{|l|}{ Growing-Finishing } \\
\hline Feed cost, US\$ per animal & 58.47 & 61.58 & 5.05 \\
\hline
\end{tabular}

negative impact on feed costs, while "YES" indicates where the AGP use is necessary to avoid economic losses. The model measures changes within each variable (by defining them as ranges) to enable AGP withdrawal without incurring an economic feed loss. For example, if the difference in feed conversion between the AGP + and AGP- diets do not exceed $0.5 \%$ and AGP price increases five-fold over the current price, AGP can be eliminated with no impact on feed costs. However, considering the current AGP price and the difference in feed conversion ratio between the two diets $15.5 \%$ in the growing-finishing phase and $3.5 \%$ in the post-weaning phase), an impact on feed costs is expected. If AGP price is halved, with zero variation in feed conversion, AGP withdrawal has no negative impact on feed costs.

\section{Discussion}

The results of this study showed an evident link between the use of AGP and the performance results in the rearing phase of pigs. In addition, there is no relationship between feed intake and the AGP use. Laxminarayan et al. (2015) reported that AGP might reduce efficiency over the years, possibly due to different factors in the production system, such as optimization of conditions and increasing level of bacterial resistance to AGP. In the present study, there was no difference for the "year of publication" factor when the statistical model was created, which demonstrates no great variation in the weight of the animals during the years of publication of the studies. This may be associated to the fact that the articles that contained a health challenge were not used in the meta-analysis. Without the health challenge, the presence of pathogenic bacteria is significantly reduced, and the performance of animals undergoes less variation.

Different mechanisms of action have been theorized over time; however, it is still unclear how AGP works in the body of pigs. Knarreborg et al. (2004) and Smith et al. (2014) associated the AGP effect on growth with a decrease in the activity of bile salt hydrolase (BSH). Conjugated bile acids are essential for lipid solubilization and micelle formation, as bile acids are the main BSH substrates. Energy production is reduced when BSH deconjugates bile acids because this action compromises lipid metabolism (Smith et al., 2014). Dibner and Richards (2005), Rettedal et al. (2009), and Castillo et al. (2007) reported that the effect of AGP on performance is linked to the intestinal microbiota modulation, reducing the number of pathogenic bacteria, and allowing an increase in the population of bacteria considered beneficial to animal growth. The intestinal microbiome influences a variety of processes within the body, such as immunological, physiological, and nutritional changes, and it also helps protect the gastrointestinal tract (Dibner and Richards, 2005). Therefore, the microbial polulation affects the general health and performance of pigs. Although the composition of gut microbiota varies among pigs, when a diet containing AGP was provided to the animals, there was a reduction in Lactobacillus johnsonii, Clostridiales, and Turicibacter and the increase of Lactobacillus amylovorus in the ileum (Rettedal et al., 2009). Another hypothesis created is that AGP could significantly change the intestinal physiology. In addition to nutrient absorption, the intestine has an important immune function (Round et al., 2010). There is a state of constant intestinal inflammation caused by direct contact of the intestinal wall with the microbiota (Biancone et al., 2002), which could cause greater permeability of the intestine and absorption of macromolecules (MacDonald and Monteleone, 2005). AGP has the capacity to accumulate within inflammatory cells and, as a consequence, it inhibits the release of cytokines, reducing the innate inflammatory response of the animal (Labro, 1998; Labro, 2000). Furthermore, the use of AGP reduces the expression of nuclear factor kappa $\mathrm{B}(\mathrm{NF \kappa} \mathrm{B})$ in some organs, such as mesenteric lymph nodes, liver, ileum, and colon, suggesting a decrease in the inflammatory response of these tissues by avilamycin (Kroismayr et al., 2008). Therefore, more energy resources are allocated to anabolic processes, because catabolic costs are reduced in response to the use of AGP (Niewold, 2007). 
Stress factors, such as social, psychological, environmental and nutritional conditions make the post-weaning phase a critical and stressful period for pigs (Lallès et al., 2004; Heo et al., 2015). During this period, piglets experience withdrawal from the milk of the sow and must adapt to a new and less digestible diet with some anti-nutritional properties. The hypothesis of a reduced intestinal inflammatory response (Kroismayr et al., 2008; Niewold, 2007) may be an explanation of the positive correlation between AGP and piglet weight gain in post-weaning. Conversely, pigs in the finishing phases suffer less with stressors, due to their increased ability to synthesize immunoglobulins (Cromwell, 2001), limiting the response to dietary AGP in this phase.

When AGP was analyzed individually, a greater difference in performance was observed in animals that received peptides (Bacitracin), macrolides (Tylosin), and orthoscinicin (Avilamycin), and the smallest differences in performance were observed in the macrolides Tiamulin and Lincomycin, and polymyxins (Colistin). Even some AGP belonging to the same general classification had different effects, and this behavior could be reflected in the roles that AGP plays in different action mechanisms in the organism, which result in rearing-phase-specific action. AGP molecules can be divided into different groups based on the accumulation within inflammatory cells, for example: non-cumulative, cumulative without inhibition of cell function and cumulative with inhibition of cell function (Niewold, 2007). It has been reported that cyclins, macrolides, and peptides can accumulate in phagocytes and inhibit cytokine release (Labro, 2000). Another method of action proposed for AGP is the inhibition of BSH activity. Tetracyclines were considered to be consistently potent BSH inhibitors. Roxarsone and oxytetracycline inhibit the BSH activity by more than $95 \%$. $\beta$-lactams and lincosamide were considered to have relatively minor inhibitory effects. Macrolides and peptides were considered weak to reduce the BSH activity (Smith et al., 2014). AGP have an impact on the intestinal microbiota, but there are still questions about their mode of action. The use of tylosin (macrolide) inhibits the growth of gram-positive and some gramnegative bacteria. A reduction in Clostridium perfringens was observed in chickens (Collier et al., 2003). Another study reported that tylosin accelerated the change in intestinal microbiota that normally occurs throughout the life of the host, then the eubiosis stage could be reached earlier (Kim et al., 2016). Another macrolide, tiamulin, increases the population size of Firmicutes (Lactobacillus amylovorus) in the ileum of weaned piglets (Brousseau et al., 2015). The increase in Firmicute population brings the benefit of metabolizing lactic acid to butyric acid, which develops anti-inflammatory effects. As can be seen throughout the discussion, there are several mechanisms of action for AGP and they vary according to the AGP used. Thus, it is not possible to attribute the effects on the performance of animals to a single mode of action. We hypothesize that the effect on performance is a sum of different modes of action.
Several studies have estimated the economic impact caused by the withdrawal of AGP from the pig industry. In our study, the impact on feed costs is US\$ 0.86 per animal in post-weaned and US\$ 3.11 per pig in the growing-finishing phase. Miller et al. (2005) and Brorsen (2002) suggest US\$ 1.37 and US\$ 2.33 per pig, respectively. The large differences in the results may be linked to the factors considered to generate the economic models. Some costs within the production system are difficult to calculate and are not included in the models of economic impact (Kjeldsen and Callesen, 2006), such as the cost of inserting biosecurity measures on farms, potential veterinary cost, or the cost to improve the rearing facilities, as the level of technification of farms is quite variable. Factors such as farm size, size of the pig herd, types of contract, and productive practices are variable within the pig industry. These factors affect the simulation of economic impact and, therefore, the effect is different for each producer, depending on the reality of the farm (McBride et al., 2008; MacDonald and Wang, 2011). The model built in this study was based on pig feeding and changes in performance, and this model can be part of a more complete analysis, considering aspects of health challenge, cost of production structure, costs of investment in biosecurity, period of use of the facilities, among others. The future composition of a more complex model may also consider social factors in relation to bacterial resistance. The model created in this study is simple, nevertheless, it provides important and direct information to the swine industry, assisting in the decision-making process. In this study, the simulation of economic impact was performed using data provided by Brazilian companies, such as the feed cost, and the performance data was obtained by the meta-analysis of several studies. However, the equations are easy to understand and production data from different countries could be inserted into the equation to perform a new simulation. The sensitivity analysis could be performed with other variables within the equation of economic impact simulation, such as weight gain and feed price, as well as the various levels used could be modified according to the reality of the situation to be simulated.

The main performance variables that compose the equations are weight gain and feed conversion. To better understand our findings regarding the impact on feed costs, it is safe to consider that increased feed costs are due to AGP use, which conversely reduces feed cost by increasing the feed conversion ratio. The higher feed cost found in this study is directly linked to a reduction in pig performance (meta-analysis result). Considering the current AGP price and better result of feed conversion with AGP use, the results of postweaning highlighted an increase of $3.4 \%$ in feed costs per pig when AGP is withdrawn from the feed. However, 
if the difference in feed conversion between AGP + and AGP- diets is equal to zero, there is no increase in feed costs and AGP could be withdrawn from the pig diet, as suggested by the results of the sensitivity analysis. To obtain a smaller difference between the feed conversion of pigs that receive or not AGP, efficient management strategies are necessary to reduce pathogens on farms and increase significantly the biosafety level (Laanen et al., 2014; Silva et al., 2019, McKenzie and Carter, 2019), as well as the conduction of effective vaccination programs to ensure health and minimize the risk of secondary diseases in the herd (Holyoake et al., 2009). It is necessary to improve the ambience, focusing on climate and structural conditions of the facilities for better performance rates, allowing to reduce the use of AGP. Besides, it is necessary to take animal welfare into account as a fundamental point, since the performance and reduction of diseases are closely linked to this factor (Van Dixhoorn et al., 2016; Dawkins, 2019).

Withdrawing AGP from the pig diet without increasing costs requires the implementation of new nutritional strategies. Several feed additives, such as enzymes, organic acids, essential oils, probiotics and prebiotics, have been studied to understand their mechanisms of action and become possible substitutes for AGP (Tracker, 2013; Vieira et al., 2020). Probiotics improved gut health (Tracker, 2013; Badia et al., 2012) and demonstrated an capacity to affect the presence of pro-inflammatory cytokines and chemokines in vitro or in the gut microbiota of pigs (Upadrasta et al., 2013). It is possible to reduce the difference in feed conversion between pigs fed AGP + and AGP diets; however, producers in the same country are in different production conditions and there are also major differences in production systems between countries. There is a long way for all producers to be able to remove AGP from the pig diet without compromising performance and production costs. It is necessary to evaluate different strategies and indetify the best strategy within the reality of each producer to improve yield without the use of AGP. It is also essential to analyze all factors that directly interfere in production costs.

The use of AGP improves weight gain and feed conversion in post-weaning piglets. Higher feed conversion ratios were also shown in the growthfinishing pigs fed AGP + diets. The generated equation allowed a simulation of the economic impact on feed costs and demonstrated that the reduction in performance caused by the withdrawal of AGP results in economic losses. However, the sensitivity analysis showed situations in which there is a possibility to raise pigs without the use ofAGP.

\section{Acknowledgments}

The authors thank the Animal Science Laboratory Federal University of Rio Grande do Sul (UFRGS) for the assistance during the development of the study.

\section{Authors' Contributions}

Conceptualization: Cardinal, K.M.; Ribeiro, A.M.L.; Andretta, I.; Kipper, M. Data acquisition: Cardinal, K.M.; Andretta, I.; Kipper, M. Design of methodology: Cardinal, K.M.; Andretta, I.; Kipper, M.; Ribeiro, A.M.L. Writing and editing: Cardinal, K.M.; Andretta, I.; Kipper, M.; Stefanello, T.B.; Schroeder, B.; Ribeiro, A.M.L.

\section{References}

Badia, R.; Zanello, G.; Chevaleyre, C.; Lizardo, R.; Meurens, F.; Martínez, P.; Brufau, J.; Salmon, H. 2012. Effect of Saccharomyces cerevisiae var. Boulardii and $\beta$-galactomannan oligosaccharide on porcine intestinal epithelial and dendritic cells challenged in vitro with Escherichia coli F4 (K88). Veterinary Research 43: 4.

Biancone, L.; Monteleone, I.; Blanco, G.D.V.; Vavassori, P.; Pallone, F. 2002. Resident bacterial flora and immune system. Digestive and Liver Disease 34: 37-43.

Brorsen, B.W.; Lehenbauer, T.; Ji, D.; Connor, J. 2002. Economic impacts of banning subtherapeutic use of antibiotics in swine production. Journal of Agricultural and Applied Economics 34: 489-500

Brousseau, J.P.; Talbot, G.; Beaudoin, F.; Lauzon, K.; Roy, D.; Lessard, M. 2015. Effects of probiotics Pediococcus acidilactici strain MA18/5M and Saccharomyces cerevisiae subsp. boulardii strain SB-CNCM I-1079 on fecal and intestinal microbiota of nursing and weanling piglets. Journal of Animal Science 93: 5313-5326.

Cardinal, K.M.; Kipper, M.; Andretta, I.; Ribeiro, A.M.L. 2019. Withdrawal of antibiotic growth promoters from broiler diets: performance indexes and economic impact. Poultry Science 98: 6659-6667.

Castillo, M.; Martín-Orúe, S.M.; Nofrarías, M.; Manzanilla, E.G.; Gasa, J. 2007. Changes in caecal microbiota and mucosal morphology of weaned pigs. Veterinary Microbiology 124: 239247.

Collier, C.T.; Van der Klis, J.D.; Deplancke, B.; Anderson, D.B.; Gaskins, H.R. 2003. Effects of tylosin on bacterial mucolysis, Clostridium perfringens colonization, and intestinal barrier function in a chick model of necrotic enteritis. Antimicrobial Agents and Chemotherapy 47: 3311-3317.

Cromwell, G. 2001. Antimicrobial and promicrobial agents. p. 401-426. In: Lewis, A.J.; Southern, L.L., eds. Swine nutrition. CRC Press, Boca Raton, FL, USA.

Davies, M.; Walsh, T.R. 2018. A colistin crisis in India. The Lancet Infectious Diseases 18: 256-257.

Dawkins, M.S. 2019. Animal welfare as preventative medicine. Animal Welfare 28: 1-17.

Dibner, J.J.; Richards, J.D. 2005. Antibiotic growth promoters in agriculture: history and mode of action. Poultry Science 84: 634-643.

Fairbrother, J.M.; Nadeau, É.; Gyles, C.L. 2005. Escherichia coli in postweaning diarrhea in pigs: an update on bacterial types, pathogenesis, and prevention strategies. Animal Health Research Reviews 6: 17-39. 
Food and Drug Administration [FDA]. 2019. Animal drugs and animal food additives. Avaliable at: https://www.fda.gov/animalveterinary/development-approval-process/veterinary-feeddirective-vfd [Accessed Apr 8, 2020]

Goutard, F.L.; Bordier, M.; Calba, C.; Erlacher-Vindel, E.; Góchez, D.; de Balogh, K.; Benigno, C.; Kalpravidh, W.; Roger, F.; Vong, S. 2017. Antimicrobial policy interventions in food animal production in south east Asia. The British Medical Journal 358: 36-41.

Heo, J.M.; Woyengo, T.A.; Kahindi, R.K.; Kiarie, E.; Maiti, P.K.; Nyachoti, C.M. 2015. Ileal amino acid digestibility in egg from hyperimmunized-hens fed to weaned pigs and piglet response to diets contain egg products. Animal Feed Science and Technology 204: 52-61.

Holyoake, P.; Collins, A.; Donahoo, M.; Lising, R.; Emery, D. 2009. Identifying obstacles to reducing the use of antibiotics to control porcine proliferative enteropathy. Australian Veterinary Journal 87: 33-34.

Kahn, L.H. 2016. One Health and the Politics of Antimicrobial Resistance. J.H.U. Press, Baltimore, MD, USA.

Kim, J.; Guevarra, R.B.; Nguyen, S.G.; Lee, J.H.; Jeong, D.K.; Unno. T. 2016. Effects of the antibiotics growth promoter tylosin on swine gut microbiota. Journal of Microbiology and Biotechnology 26: 876-882.

Kjeldsen, N.; Callesen, J. 2006. Terminated use of antimicrobial growth promoters in pig production in Denmark: effects on pig welfare and productivity. p. 127-135 In: Barug, D.; de Jong, J.; Kies, A.K.; Verstegen, M.W.A., eds. Antimicrobial growth promoters: where do we go from here. Wageningen Academic Publishers, Wageningen, The Netherlands.

Knarreborg, A.; Lauridsen, C.; Engberg, R.M.; Jensen, S.K. 2004. Dietary antibiotic growth promoters enhance the bioavailability of $\alpha$-tocopheryl acetate in broilers by altering lipid absorption. The Journal of Nutrition 134: 1487-1492.

Kroismayr, A.; Sehm, J.; Pfaffl, M.W.; Schedle, K.; Plitzner, C.; Windisch, W. 2008. Effects of avilamycin and essential oils on mRNA expression of apoptotic and inflammatory markers and gut morphology of piglets. Czech Journal of Animal Science 53: 377-387.

Laanen, M.; Maes, D.; Hendriksen, C.; Gelaude, P.; De Vliegher, S.; Rosseel, Y.; Dewulf. J. 2014. Pig, cattle and poultry farmers with a known interest in research have comparable perspectives on disease prevention and on-farm biosecurity. Preventive Veterinary Medicine 115: 1-9.

Labro, M.T. 1998. Antibacterial agents-phagocytes: new concepts for old in immunomodulation. International Journal of Antimicrobial Agents. 10: 11-21.

Labro, M.T. 2000. Interference of antibacterial agents with phagocyte functions: immunomodulation or "immuno-fairy tales"? Clinical Microbiology Reviews 13: 615-650.

Lallès, J.P.; Boudry, G.; Favier, C.; Le Floc'h, N.; Luron, I.; Montagne, L.; Oswald, I.P.; Pié, S.; Pié, C.; Sève, B. 2004. Gut function and dysfunction in young pigs: physiology. Animal Research 53: 301316.

Laxminarayan, R.; Van Boeckel, T.; Teillant, A. 2015. The economic costs of withdrawing antimicrobial growth promoters from the livestock sector. Available at: https://oecd-ilibrary.org/agricultureand-food/the-economic-costs-of-withdrawing-anti-microbial-usein-the-livestock-sector_5js64kst5wvl-en [Accessed May 7, 2019]
Li, K.; Xiao, Y.; Chen, J.; Chen, J.; He, X.; Yang, H. 2017. Microbial composition in different gut locations of weaning piglets receiving antibiotics. Asian-Australasian Journal of Animal Sciences 30: 78-84.

Li, P.; Piao, X.; Ru, Y.; Han, X.; Xue, L.; Zhang, H. 2012. Effects of adding essential oil to the diet of weaned pigs on performance, nutrient utilization, immune response and intestinal health. Asian Australasian Journal of Animal Sciences 25: 1617-1626.

Long, S.F.; Xu, Y.T.; Pan, L.; Wang, Q.Q.; Wang, C.L.; Wu, J.Y.; Wu, Y.Y.; Han, Y. M.; Yun, C.H.; Piao, X.S. 2018. Mixed organic acids as antibiotic substitutes improve performance, serum immunity, intestinal morphology, and microbiota for weaned piglets. Animal Feed Science and Technology 235: 23-32.

Lovatto, P.A.; Lehnen, C.; Andretta, I.; Carvalho, A.; Hauschild, L. 2007. Meta analysis in scientific research: a methodological approach . Revista Brasileira de Zootecnia 36: 285-294 (in Portuguese, with abstract in English).

MacDonald, J.M.; Wang, S.L. 2011. Foregoing sub-therapeutic antibiotics: the impact on broiler grow-out operations. Applied Economic Perspectives and Policy 33: 79-98.

MacDonald, T.T.; Monteleone, G. 2005. Immunity, inflammation, and allergy in the gut. Science 307: 1920-1925.

McKenzie, P.; Carter, R. 2019. Change management reduces antibiotic use on pig farms. Australian Veterinary Journal 97: 233-234.

McBride, W.D.; Key, N.; Mathews, K.H. 2008. Subtherapeutic antibiotics and productivity in U.S. hog production. Applied Economic Perspectives and Policy 30: 270-288.

Miller, G.Y.; Liu, X.; McNamara, P.E.; Bush, E.J. 2005. Farmlevel impacts of banning growth- promoting antibiotic use in U.S. pig grower/finisher operations. Journal of Agribusiness 23: $147-162$.

Ministério da Agricultura, Pecuária e Abastecimento [MAPA]. 2020. Normative instruction of January 13, 2020 = Instrução normativa de 13 de janeiro de 2020. Avaliable at: http://in.gov. br/en/web/dou/-/instrucao-normativa-n-1-de-13-de-janeirode-2020-239402385 [Accessed Jan 7, 2020] (in Portuguese).

Niewold, T. 2007. The nonantibiotic anti-inflammatory effect of antimicrobial growth promoters, the real mode of action? A hypothesis. Poultry Science 86: 605-609.

Perina, D.P.; Sbardella, M.; de Andrade, C.; Berenchtein, B.; de Freitas, L.W.; Amigo, C.R.; Miyada, V.S. 2014. Effects of sorbitol or an antimicrobial agent on performance, diarrhea, feed digestibility, and organ weight of weanling pigs. Livestock Science 164: 144-148.

Rettedal, E.; Vilain, S.; Lindblom, S.; Lehnert, K.; Scofield, C.; George, S.; Clay, S.; Kaushik, R.S.; Rosa, A.J.M.; Francis, D.; Brozel, V.S. 2009. Alteration of the ileal microbiota of weanling piglets by the growth-promoting antibiotic chlortetracycline. Applied and Environmental Microbiology 75: 5489-5495.

Round, J.L.; O'Connell, R.M.; Mazmanian, S.K. 2010. Coordination of tolerogenic immune responses by the commensal microbiota. Journal of Autoimmunity 34: 220225.

Saltelli, A.; Chan, K.; Scott, E.M. 2000. Sensitivity Analysis. John Wiley, New York, NY, USA. 
Sauvant, D.; Schmidely, P.; Daudin, J. 2005. Meta-analyzes of experimental data: applications in animal nutrition $=$ Les méta-analyses des données expérimentales: applications en nutrition animale. INRA Productions Animales 18: $63-73$ (in French).

Silva, C.A.; Agostini, P.S.; Callegari, M.A.; Santos, R.K.S.; Novais, A.K.; Pierozan, C.R.; Pereira Junior, M.; Alves, J.B.; Gasó, J.G. 2016. Factors affecting the performance of pigs in the growing and finishing phases. Pesquisa Agropecuária Brasileira 51: 1780-1788 (in Portuguese, with abstract in English).

Silva, G.S.; Leotti, V.B.; Castro, S.M.; Medeiros, A.A.; Silva, A.P.; Linhares, D.C.; Corbellini, L.G. 2019. Assessment of biosecurity practices and development of a scoring system in swine farms using item response theory. Preventive Veterinary Medicine 167: 128-136.

Sindicato Nacional de Indústria de Alimentação Animal [Sindirações]. 2009. Brazilian Compendium of Animal Feed = Compêndio Brasileiro de Alimentação Animal. Sindirações, São Paulo, SP, Brazil (in Portuguese).

Smith, K.; Zeng, X.; Lin, J. 2014. Discovery of bile salt hydrolase inhibitors using an efficient high-throughput screening system. PLoS One 9: e85344.

Tang, K.L.; Caffrey, N.P.; Nóbrega, D.B.; Cork, S.C.; Ronksley, P.E.; Barkema, H.W.; Polachek, A.J.; Ganshorn, H.; Sharma, N.; Kellner, J.D. Ghali, W.A. 2017. Restricting the use of antibiotics in food-producing animals and its associations with antibiotic resistance in food-producing animals and human beings: a systematic review and meta-analysis. The Lancet Planetary Health 1: 316-327.

Thacker, P.A. 2013. Alternatives to antibiotics as growth promoters for use in swine production: a review. Journal of Animal Science and Biotechnology 4: 35.

Upadrasta, A.; O'Sullivan, L.; O'Sullivan, O.; Sexton, N.; Lawlor, P.G.; Hill, C.; Fitzgerald, G.F.; Stanton, C.; Ross, R.P. 2013. The effect of dietary supplementation with spent cider yeast on the swine distal gut microbiome. PloS One 8: e75714.

United States Department of Agriculture [USDA]. 2016. Phases out Growth Promotion Usage of Antibiotics in Feed. USDA, Washington, DC, USA. Available at: https://fas.usda.gov/data/ vietnam-mard-phases-out-growth-promotion-usage-antibioticsfeed [Accessed Jan 11, 2020]
Valchev, G.; Popova-Ralcheva, S.; Bonovska, M.; Zaprianova, I.; Gudev, D. 2009. Effect of dietary supplements of herb extracts on performance in growing pigs. Biotechnology in Animal Husbandry 25: 859-870.

Van Dixhoorn, I.D.; Reimert, I.; Middelkoop, J.; Bolhuis, J.E.; Wisselink, H.J.; Koerkamp, P.W.G.; Kemp, B.; StockhofeZurwieden, N. 2016. Enriched housing reduces disease susceptibility to co-infection with porcine reproductive and respiratory virus (PRRSV) and Actinobacillus pleuropneumoniae (A. pleuropneumoniae) in young pigs. PloS One. 11: e0161832.

Verstegen, M.W.; Williams, B.A. 2002. Alternatives to the use of antibiotics as growth promoters for monogastric animals. Animal Biotechnology 13: 113-127.

Vieira, A.M.; Soratto, T.A.T.; Cardinal, K.M.; Wagner, G.; Hauptli, L.; Lima, A.L.F.; Dahlke, F.; Peres Netto, D.; Moraes, P.D.O.; Ribeiro, A.M.L. 2020. Modulation of the intestinal microbiota of broilers supplemented with monensin or functional oils in response to challenge by Eimeria spp. PloS One 15: e0237118.

World Health Organization [WHO]. 2018. Antibiotic resistance. Available at: https://who.int/news-room/fact-sheets/detail/ antibiotic-resistance [Accessed Mar 21, 2020]

Yang, C.M.; Ferket, P.R.; Hong, Q.H.; Zhou, J.; Cao, G.; Zhou, L.; Chen, A. 2012. Effect of chito-oligosaccharide on growth performance, intestinal barrier function, intestinal morphology and cecal microflora in weaned pigs. Journal of Animal Science 90: 2671-2676.

Yoon, J.H.; Ingale, S.L.; Kim, J.S.; Kim, K.H.; Lee, S.H.; Park, Y.K.; Lee, S.C.; Kwon, I.K.; Chae, B.J. 2014. Effects of dietary supplementation of synthetic antimicrobial peptide-A3 and P5 on growth performance, apparent total tract digestibility of nutrients, fecal and intestinal microflora and intestinal morphology in weanling pigs. Livestock Science 159: 53-60. 